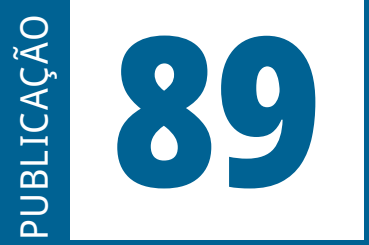

ISSN: 0101-9562

ISSN ELETRÔNICO: 2177-7055

SEQÜÊNCIA

Publicação do

Estudos jurídicos

e políticos

Programa de Pós-Graduação em Direito da UFSC

VOLUME 42 - ANO 2021 
SEQUÊNCIA - ESTUDOS JURÍDICOS E POLÍTICOS é uma publicação temática e de periodicidade quadrimestral, editada pelo Programa de Pós-Graduação Stricto Sensu em Direito da Universidade Federal de Santa Catarina - UFSC.

SEQUÊNCIA - ESTUDOS JURÍDICOS E POLÍTICOS is a thematic publication, printed every four months, edited by the Program in law of the Federal University of Santa Catarina - UFSC.

Versão eletrônica: http://www.periodicos.ufsc.br/index.php/sequencia

A publicação é indexada nas seguintes bases de dados e diretórios/

The Publication is indexed in the following databases and directories:

Base OJS

Base PKP

CCN (Catálogo Coletivo Nacional)

Dialnet

DOAJ (Directory of Open Access Journals)

EBSCOhost

Genamics Journalseek

ICAP (Indexação Compartilhada de Artigos de Periódicos)

Latindex

LivRe!

OJS
PKP
Portal de Periódicos UFSC
Portal do SEER
ProQuest
SciELO
Sherpa/Romeo
Sumarios.org
ULRICH'S
vLex

Ficha catalográfica

Seqüência: Estudos jurídicos e políticos. Universidade Federal de Santa Catarina.

Programa de Pós-Graduação em Direito. n.1 (janeiro 1980)-.

Florianópolis: Fundação José Boiteux. 1980-.

Publicação contínua

Resumo em português e inglês

Versão impressa ISSN 0101-9562

Versão on-line ISSN 2177-7055

1. Ciência jurídica. 2. Teoria política. 3. Filosoia do direito. 4. Periódicos.

I. Universidade Federal de Santa Catarina. Programa de Pós-graduação em

Direito

CDU 34(05)

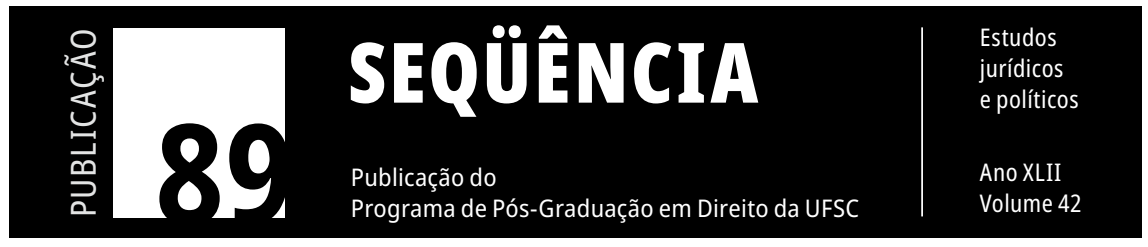




\title{
Políticas judiciárias e insuficiência de accountability: processo eletrônico x taxa de congestionamento na justiça do trabalho
}

\author{
Judiciary policies and lack of accountabillity: \\ electronic procedure x pending cases in labour courts
}

\author{
Lourival Barão Marques Filho ${ }^{1}$ \\ ${ }^{1}$ Pontíficia Universidade Católica do Paraná, Curitiba, Brasil \\ Flávio Garcia Cabral \\ ${ }^{2}$ Escola de Direito do Ministério Público \\ em Mato Grosso do Sul, Campo Grande, Brasil
}

RESUMO: A problemática deste artigo é analisar a eficiência do processo eletrônico como ferramenta de redução da taxa de congestionamento na Justiça do Trabalho e, para tanto, utiliza-se o método de abordagem indutivo e o procedimento estatístico. A conclusão obtida é contraintuitiva, na medida em que se constata que o processo eletrônico não se consubstanciou como um mecanismo que melhora a eficiência e o desempenho dos tribunais. Dado o déficit de accountability do CNJ não houve revisão da política judiciária implementada a despeito de os resultados não serem atingidos. Sugere-se a utilização da accountability na dimensão social como forma de o CNJ prestar contas acerca das políticas judiciárias.

Palavras-Chave: Accountability - Políticas judiciárias - Processo eletrônico - Taxa de congestionamento. Conclusão contraintuitiva.

ABSATRACT: The problem we analyze in this article refers to the impacts of the digital justice on pending cases in Labour Courts, using an inductive method and statistics. The conclusion is unexpected, once it is verified that the electronic procedures did not act as a mechanism to improve the efficiency and the performance of the Courts. Because of the deficit of accountability of the National Council of Justice, there was no judiciary policy review related to these results 
that were not fulfilled. Therefore, it is suggested that social accountability is an alternative so that the National Council of Justice be effectively accountable about its judiciary policies.

KeYwORDS: Accountability - Judiciary policies - Digital justice - Pending cases. Counterintuitive conclusion.

\section{INTRODUÇÃO}

A partir de 2013 o Conselho Nacional de Justiça (doravante $\mathrm{CNJ}$ ) elegeu como uma de suas políticas prioritárias a implantação do processo eletrônico nos diversos ramos do Judiciário brasileiro sob o argumento de que isso traria positivo impacto na taxa de congestionamento e que ajudaria a reduzir a colossal quantidade de processos em tramitação no país. Nesse contexto, o estudo analisa a repercussão do processo eletrônico na taxa de congestionamento na Justiça do Trabalho, índice intimamente ligado com a aferição de eficiência de um Tribunal. Para tanto, utiliza os dados minerados e divulgados pelo CNJ por intermédio do Justiça em Números considerando os anos bases de 2012 (quando começa a ter relevância o processo eletrônico no sistema de justiça) a 2017 (último ano divulgado).

Faz-se, desde já, a necessária ressalva de que o artigo não se debruça sobre as causas da morosidade do Judiciário, tampouco sobre eventuais formas de resolvê-la. Outrossim, não busca criticar a implantação do processo eletrônico. O objetivo é mais limitado: é perscrutar a relação entre as variáveis a) processo eletrônico, b) taxa de congestionamento na Justiça do Trabalho e c) continuidade da política judiciária.

O estudo divide-se em três partes: na primeira, por intermédio do método de abordagem indutivo e do procedimento estatístico busca-se investigar se a intensa e célere virtualização dos processos trouxe o resultado esperado, ou seja, se a taxa de congestionamento foi afetada e, consequentemente, se houve melhora na eficiência dos 
tribunais. A seguir, esquadrinha-se o resultado desta conclusão nas políticas judiciárias conduzidas pelo CNJ e passa a abordar a penúria de controle, fiscalização e verificação das metas estabelecidas por este órgão. Na terceira parte, demonstra-se a ausência de accountability desta instituição, porquanto suas condutas comissivas e omissivas não são alvo de prestação de contas e, especialmente, de sanções pelo não atingimento da proposta inicial.

Constata-se, assim, a repetição de uma situação habitual no Judiciário brasileiro no sentido de que as políticas públicas são imaginadas e implementadas pautando-se nas evidências anedóticas, nos argumentos de autoridade e na percepção subjetiva da autoridade da ocasião, olvidando-se completamente das essenciais evidências empíricas (Yeung, 2010, p. 10); (Aragão, 2003, p. 14); (NAlini, 2014, p. 250-258); (Costandrade; Silva Júnior; Gico Júnior, 2013, p. 37-70); (Kant de Lima; Baptista, 2010); (Watanabe, 2014, p. 34); (Efing; Marques Filho, 2016, p. 439-457); (Hatmann et al., 2018, p. 399-426); (Yeung; Azevedo, 2009); (EIsenberg; Lanvers, 2009); (EPSTEIn; King, 2013, p. 14).

O artigo tem, dessa forma, o objetivo de contribuir para o debate da construção de métricas adequadas de mensuração dos principais indicadores do fenômeno da litigiosidade e demonstrar a insuficiência de accountability relativamente ao CNJ.

\section{CONSELHO NACIONAL DE JUSTIÇA E A POLÍTICA JUDICIÁRIA DO PROCESSO ELETRÔNICO}

Ao analisar os fundamentos da Resolução 185/2013 do CNJ, a qual instituiu o sistema de processo judicial eletrônico - PJe - no âmbito do Poder Judiciário é possível verificar que os objetivos eram: a) melhorar a eficiência dos tribunais; b) racionalizar a utilização dos recursos orçamentários; c) uniformizar o modelo de processo eletrônico para todos os tribunais e d) proteção ambiental. Pelo escopo 
deste artigo, a investigação será limitada à alínea “ $a$ ”. Constou expressamente no ato normativo que um dos motivos que justifica sua edição consubstancia-se: “[n]os benefícios advindos da substituição da tramitação de autos em meio físico pelo meio eletrônico, como instrumento de celeridade e qualidade da prestação jurisdicional". (Conselho Nacional de Justiça, 2013).

Inegavelmente o CNJ elegeu o processo eletrônico como mecanismo apto a trazer maior presteza na tramitação processual e aprimoramento das decisões judiciais. Estes conceitos, quais sejam, celeridade e qualidade, estão umbilicalmente ligados ao fenômeno da taxa de congestionamento apurada e divulgada pelo CNJ. Com efeito, ao se julgar mais rápido e com maior excelência diminui-se o resíduo existente e, sobretudo, atinge-se o objetivo de julgar e baixar mais processos do que a quantidade de novas ações que foram ajuizadas no ano.

A taxa de congestionamento metrifica a quantidade de processos que permaneceram sem solução comparativamente ao total tramitado no período de um ano. Quanto mais alto o índice, maior é a incapacidade do tribunal em resolver seu estoque de processos. (JustiÇA EM Números 2018: ano-base 2017, 2018, p. 90); (Fidelis, 2018, p. 73). Dito de outra forma: quanto maior o índice, mais ineficiente é o tribunal.

Assim, a Resolução 185/2013, ao invocar a celeridade e a qualidade da prestação jurisdicional como resultados inequívocos da implementação do processo eletrônico, tem como inexorável a conclusão de que o resultado esperado culminaria, também, na redução da taxa de congestionamento a fim de aprimorar a eficiência dos tribunais. Todavia, não foi isso que aconteceu e essa é a perspectiva que impulsiona o presente estudo.

\subsection{Avanço da implantação do processo eletrônico na Justiça do Trabalho: análise da série histórica}


Estimulada pela Resolução 94/2012 do Conselho Superior da Justiça do Trabalho (2012), que depois foi ratificada pela Resolução 185/2013 do CNJ, a Justiça do Trabalho, a partir de 2012, inicia um intenso e célere caminho de virtualização dos processos. De fato, sai de percentual irrisório nos anos de 2009 e 2010 para um crescimento vertiginoso a partir de 2012, alcançando já em 2014 o índice de $63,9 \%$ de processos eletrônicos nos casos novos no primeiro grau de jurisdição como demonstra o gráfico abaixo:

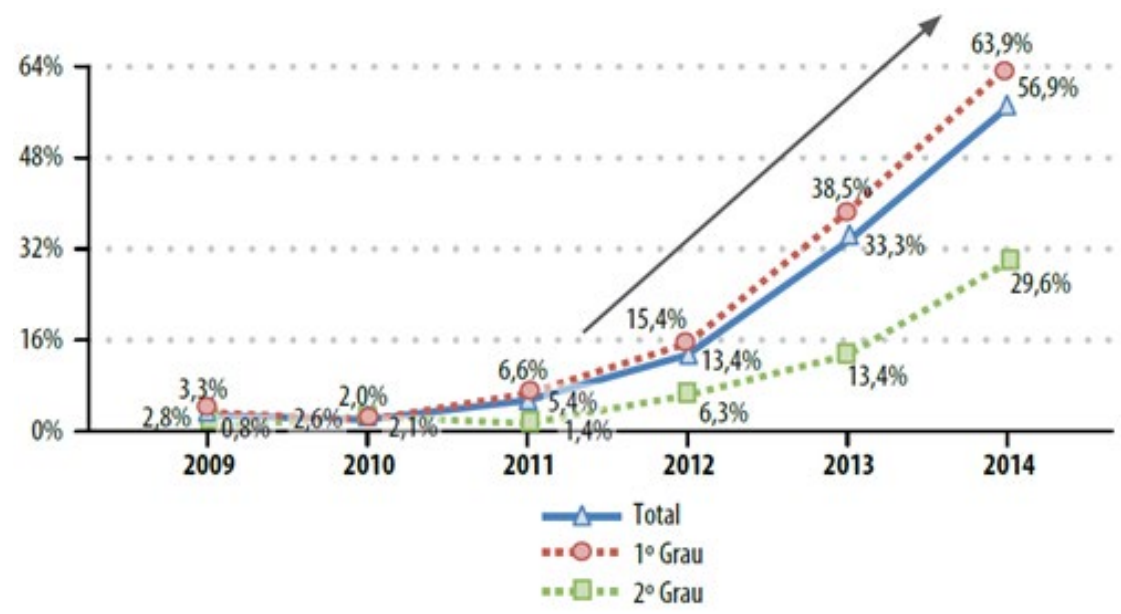

Gráfico 1 - Série histórica do percentual de casos novos eletrônicos na Justiça do Trabalho. Fonte: CNJ (JustiçA Em Números 2015: ano-base 2014, p. 185)

Nos anos seguintes o processo de expansão do processo eletrônico foi mantido e em 2017 atingiu 96,3\% dos casos novos, sendo que alguns tribunais, como o Tribunal Regional do Trabalho da $9^{\text {a }}$ Região ${ }^{1}$, alcançou a integralidade de processos eletrônicos, como se observa na figura a seguir:

1 Com jurisdição no Estado do Paraná. 


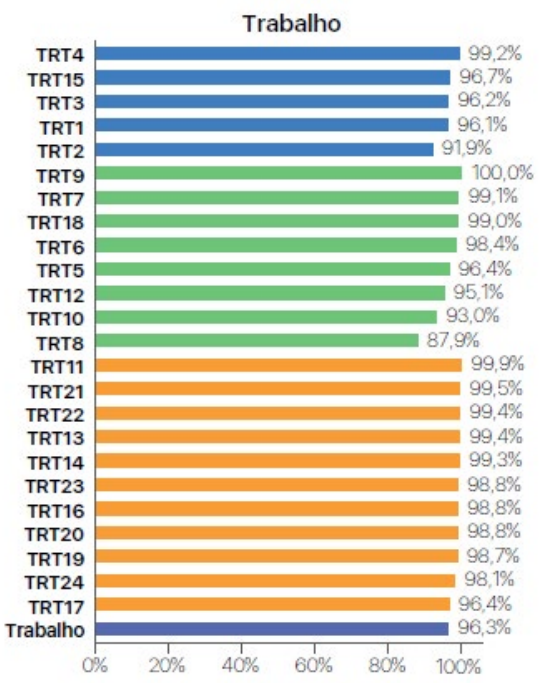

Figura 1 - Percentual de casos novos eletrônicos, por TRT, em 2017. Fonte: CNJ (JUSTIÇA EM NúmeRos 2018: ano-base 2017, 2018, p. 95).

Observa-se, assim, que a primeira medida foi atingida: a utilização do processo eletrônico por toda a Justiça do Trabalho. Trata-se, sem dúvida, de um sucesso administrativo logístico desta Justiça Especializada que, em reduzido espaço temporal, conseguiu que praticamente todos os casos novos tramitassem por meio eletrônico. Assim, ao consolidar o processo eletrônico como modalidade única de tramitação processual, tinha o CNJ a expectativa de melhorar o seu indicador de eficiência, ou seja, a taxa de congestionamento. Porém, não foi isso que se observou.

Não se está aqui a criticar a implantação do processo eletrônico, que, sem dúvida alguma, é um relevante mecanismo de aprimoramento da gestão processual. O problema é que a implementação do processo eletrônico, isoladamente e sem uma completa revisão da gestão burocrática, não alcança a finalidade proposta, ou seja, não melhora a efetividade do Judiciário. Isso se verifica porque a taxa de congestionamento, apta a mensurar essa grandeza, não diminuiu mesmo após a Justiça do Trabalho atingir praticamente 100\% de processo eletrônico. 
É inegável que o processo eletrônico trouxe inúmeras vantagens a todo o sistema de justiça que foram resumidas da seguinte forma por Rotta et al (2013, p. 125-154): a) ubiquidade do processo judicial digital: possibilidade de acompanhar os atos praticados a qualquer momento e em qualquer lugar; b) acesso remoto: desnecessidade de deslocamento físico dos advogados até o Fórum para a realização dos atos processuais; c) segurança digital: certificação e assinatura digital, a qual permite a realização dos atos processuais com a segurança, autenticidade e celeridade; d) eliminação do papel.

Comunga-se integralmente do entendimento exposto, no sentido de que o processo eletrônico é superior ao processo físico, situação, na verdade, já consolidada no âmbito da administração da justiça. $\mathrm{O}$ que se busca investigar, em virtude da proposta deste trabalho, é o quanto ele (não) contribuiu para o comportamento da taxa de congestionamento e consequente maior eficiência do processo do trabalho.

\subsection{Taxa de congestionamento: conceito e objetivo}

Segundo o CNJ a taxa de congestionamento: "mede a efetividade do tribunal em um período, levando-se em conta o total de casos novos que ingressaram, os casos baixados e o estoque pendente ao final do período anterior ao período base." (Conselho NacioNAL DE JustiçA, 2014) Ainda, de acordo com o CNJ, este indicador “tem analogia direta com uma caixa de água, que quando dá vazão ao volume que entra e mantém um nível baixo, resulta numa baixa taxa de congestionamento. Ao contrário, quando não dá vazão ao que entra e ainda mantém um estoque alto resulta numa alta taxa de congestionamento.” (Conselho Nacional de Justiça, 2014).

A taxa de congestionamento é representada pela fórmula (TPJB /(TCN + TCP)), onde: TPJB - Total de processos judiciais baixados; TCN - Total de casos novos; TCP - Total de casos pendentes.

Conforme a Resolução 76/2009 do CNJ (2009), processos baixados são aqueles: a) que foram arquivados definitivamente; b) nos quais 
houve decisões que transitaram em julgado e iniciou-se a liquidação, cumprimento ou execução; c) que foram remetidos para outros órgãos judiciais competentes, desde que vinculados a tribunais diversos; d) que foram remetidos para as instâncias superiores ou inferiores. Por sua vez, casos pendentes são todos os processos que nunca receberam movimento de baixa.

Assim, a taxa de congestionamento é o resultado da divisão do total de processos baixados pela soma dos casos novos e pendentes e tem por desiderato mensurar a efetividade do tribunal na solução dos processos que lhe são confiados. Taxa de congestionamento está vinculada de modo indissociável aos conceitos de celeridade e qualidade - para utilizar os termos contidos na Resolução 185/2013 do CNJ - porquanto mais eficiente será o tribunal que julgue/baixe maior quantidade de processos, em menor tempo e com mais acurácia.

Tribunal eficiente, ou melhor, sistema de justiça eficiente é aquele que possui baixa taxa de congestionamento, porquanto tem a capacidade de solucionar (julgar/baixar) com celeridade e qualidade as demandas que lhe são submetidas, metabolizando os casos novos recebidos e, ainda, com redução do resíduo/estoque processual.

\subsection{Evidências empíricas e a desconstrução do discurso: desfecho contraintuitivo ${ }^{2}$}

Duas questões demandam análise prévia antes da apresentação da conclusão sobre o impacto do processo eletrônico na taxa de congestionamento, na medida em que, se a resposta for positiva para elas, o argumento central do trabalho poderia ficar esvaziado: i) o aumento da taxa de congestionamento decorreu de um crescimento assimétrico das ações novas na Justiça do Trabalho no interstício temporal objeto de investigação? ii) o comportamento da taxa de congestionamento

\footnotetext{
2 "For the rational study of the law the blackletter man may be the man of the present, but the man
} of the future is the man of statistics and the master of economics." (HOLMES, 1897, p. 457). 
após a implementação do processo eletrônico nos demais ramos do Judiciário foi similar à da Justiça do Trabalho?

Passa-se a responder a primeira indagação. Poder-se-ia argumentar que a taxa de congestionamento aumentou em virtude do crescimento do número de ações no período. Nesse raciocínio, quanto maior a quantidade de novas ações, maior será a taxa de congestionamento.

Necessário, desta forma, verificar o desempenho destes indicadores no período de 2012 a 2017. Os casos novos aumentaram de 2.254.355 para 2.647.450 (Tribunal Superior do Trabalho, 2019), ou seja, tiveram crescimento de $17,43 \%$, sendo que no mesmo período a taxa de congestionamento cresceu de 51,5\% para 55,2\% (JusTiÇA EM Números 2018: ano-base 2017, 2018, p. 91), que resulta incremento proporcional de 7,18\%. Destarte, como o aumento da taxa de congestionamento foi inferior ao aumento da quantidade de novas ações, a conclusão seria de que o processo eletrônico foi relevante na solução dos processos, trazendo eficiência ao processo do trabalho.

Embora sedutor, o argumento não prospera.

Em primeiro lugar porque no conceito de taxa de congestionamento existem três grandes indicadores: casos novos, processos baixados e casos pendentes. O aumento de casos novos atinge somente um dos vetores que compõem a taxa de congestionamento, razão pela qual não teria o condão de impactar significativamente esse indicador do congestionamento. De fato, o aumento dos casos novos é pertinente somente para a fase cognitiva da demanda, ao passo que os outros dois indicadores estão relacionados com as fases recursais e de cumprimento de sentença.

Em seguida, é indispensável para a análise adequada do cruzamento dos indicadores "crescimento de casos novos" com "crescimento da taxa de congestionamento" que seja observado mais um indicador: tempo médio dos processos, cuja definição é a quantidade de dias que o processo demorou entre seu ajuizamento e a prolação da sentença.

O aumento quantitativo dos casos novos tem que ser harmônico e simétrico com o aumento do tempo médio do processo, a fim de que as novas ações sejam julgadas no mesmo espaço de tempo anterior e 
não se aumente o resíduo processual. Confrontando esses dados não é o que se constata: no período em análise o prazo médio aumentou de 173,99 dias para 238,75 dias, o que significa incremento de $37,22 \%$. Isso representa que o Judiciário Trabalhista não foi hábil a acolher e metabolizar o aumento das ações, mesmo utilizando o processo eletrônico, como demonstra a tabela a seguir:

Tabela 1 - Prazo médio x casos novos

\begin{tabular}{|c|c|c|}
\hline Anos & Prazo Médio/dias & Casos novos \\
\hline 2012 & 173,99 & 2.254 .355 \\
\hline 2013 & 157,52 & 2.371 .210 \\
\hline 2014 & 195,49 & 2.530 .691 \\
\hline 2015 & 210,23 & 2.636 .681 \\
\hline 2016 & 222,75 & 2.756 .214 \\
\hline 2017 & 238,75 & 2.647 .450 \\
\hline
\end{tabular}

Fonte: Tribunal Superior do Trabalho (2019)

Constata-se, assim, que o crescimento dos casos novos de 17,43\% gerou um aumento de prazo médio de 37,22\%. Esses aumentos são contemporâneos com a expansão e atingimento de mais de 95\% de casos novos já no formato eletrônico. Isso pode significar que o processo eletrônico isoladamente não é capaz de absorver sequer o crescimento das demandas, na medida em que aumentou o tempo médio em proporção superior ao do acréscimo das novas ações.

O processo eletrônico não se mostrou apto, portanto, a receber e digerir o aumento dos casos novos. Como se viu, o tempo médio dos processos aumentou em proporção superior ao crescimento das novas ações, justamente no período em que o processo eletrônico passou a ter protagonismo na Justiça do Trabalho.

Não tendo sido o processo eletrônico hábil a metabolizar a adição das novas demandas, também se mostra incapaz de influenciar 
os outros dois indicadores (casos pendentes e processos baixados) que compõem a taxa de congestionamento.

Nem se alegue que a utilização do indicador de casos novos eletrônicos é incompleta, porque não analisa a totalidade do acervo processual, isto é, desconsidera que existem processos físicos na Justiça do Trabalho e que isso pode ser um fator que dificultaria a redução da taxa de congestionamento. Os casos novos eletrônicos remanescem assim nas fases seguintes, ou seja, são recursos em meio eletrônico e processos de execução eletrônicos, portanto, paulatinamente todo o acervo processual vai sendo constituído em formato eletrônico. Além da transformação gradual do acervo no formato eletrônico, o CSJT adotou política judiciária, por intermédio da Resolução 185/2017 (Conselho Superior da Justiça do Trabalho, 2017), de migrar os autos físicos para eletrônicos, no que resulta que o total de processos (em todas as fases processuais) está cada vez mais próximo de alcançar a integral virtualização. Nesse contexto, é possível depreender que a expansão do processo eletrônico ocorre em todas as fases do processo do trabalho. Por conseguinte, a análise do percentual de processo eletrônico alcança todas as fases processuais, aí incluídos processos baixados e casos pendentes.

Volta-se à segunda indagação anteriormente realizada: esse é um fenômeno exclusivo da Justiça do Trabalho ou atinge todo o sistema de justiça?

A figura abaixo representa graficamente todos os ramos do Judiciário e indica que a taxa de congestionamento não sofreu influência significativa com a implantação do processo eletrônico quando se observa a integralidade do sistema de justiça: 


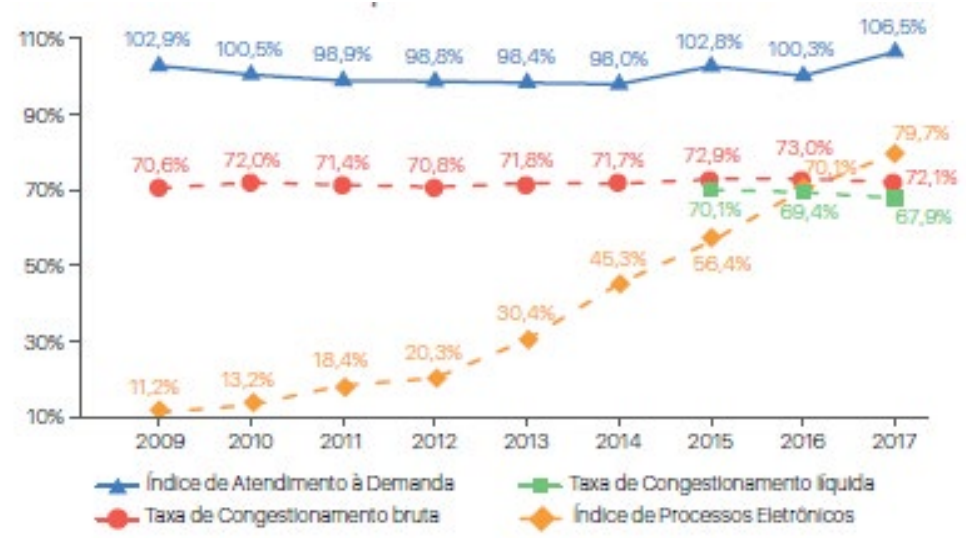

Figura 2 - Série histórica da taxa de congestionamento, do índice de atendimento à demanda e do percentual de processos eletrônicos. Fonte: CNJ (JustiçA EM NúmEROS 2018: ano-base 2017, 2018, p. 91).

Vê-se que a forte expansão do processo eletrônico, que atingiu $79,7 \%$ de casos novos em 2017, não impactou positivamente o indicador da taxa de congestionamento que permaneceu flutuando ao redor de 70\%. Tem-se, assim, que não é uma especificidade da Justiça do Trabalho que poderia ter acarretado tal fenômeno; ao revés, ele acontece em todo o sistema de justiça, o que robustece o argumento central deste artigo.

Portanto, constata-se que: a) o processo eletrônico não reduziu a taxa de congestionamento no sistema de justiça globalmente considerado; b) o tempo médio de solução dos processos cresceu mais que a quantidade de novas ações, mesmo sob a égide do processo eletrônico; c) o acervo total da Justiça do Trabalho caminha fortemente para total virtualização.

Partindo destas premissas, verticaliza-se a análise da implementação do processo eletrônico e seus desdobramentos no congestionamento da Justiça do Trabalho.

Em toda a série histórica objeto deste estudo (2012-2017) a taxa de congestionamento da Justiça do Trabalho se manteve alta, variando 
de 51,1\% em 2012 ao cume de 56,2\% em 2016. A flutuação não é expressiva, no entanto, o dado mais relevante para este estudo é que a partir da forte expansão do processo eletrônico que se dá com maior ênfase a partir de 2013, a taxa de congestionamento aumenta. Não se trata de aumento drástico, mas que desautoriza a conclusão de que o processo eletrônico seria responsável por reduzir o congestionamento, como pode ser observado na figura 3 abaixo:

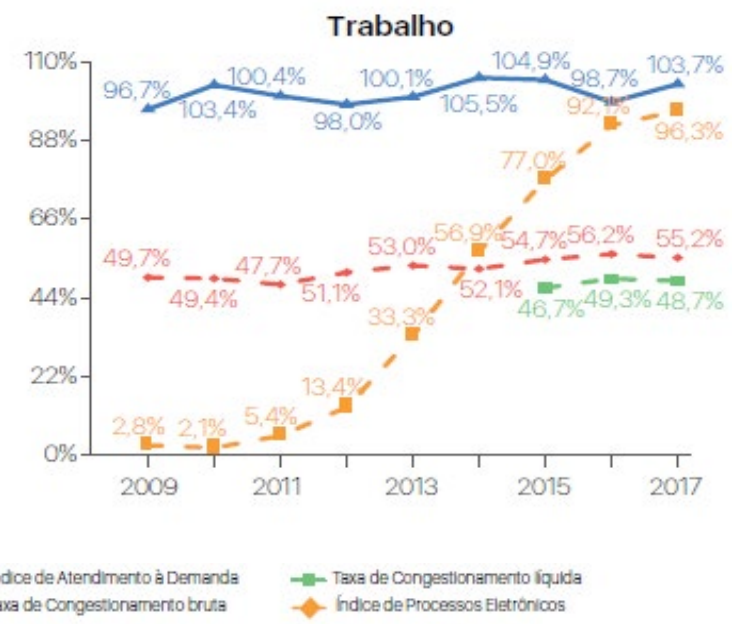

Figura 3 - Série histórica da taxa de congestionamento, do índice de atendimento à demanda e do percentual de processos eletrônicos na Justiça do Trabalho.

Fonte: CNJ (JustiçA Em Números 2018: ano-base 2017, 2018, p. 2018)33.

A análise das evidências empíricas (Merton, 2015, p. 192-235); (MARTIN-GuZMán, 2015, p. 513-521) permite a conclusão contraintuitiva

\footnotetext{
A taxa de congestionamento líquida somente passou a ser divulgada em 2015, assim optou-se por utilizar a taxa de congestionamento bruta a fim de possuir uma série histórica mais longeva. Quanto mais extensa a série histórica menor a possibilidade de se adotar movimentos cíclicos como indicativos de uma tendência geral. (KAZMIER, 2004, p. 329).
} 
de que o processo eletrônico não se consubstancia como indicador que tem o condão de reduzir a taxa de congestionamento. De fato, a despeito da supremacia que o processo eletrônico possui em comparação ao processo físico, a análise da taxa de congestionamento não permite a conclusão de que foi uma variável que trouxe real impacto na eficiência ${ }^{4}$ do Judiciário. Se a eficiência é medida pela taxa de congestionamento, segundo os critérios estabelecidos pelo próprio CNJ, observa-se que o processo eletrônico não teve êxito em melhorar esse indicador, notadamente porque o congestionamento aumenta justamente na época de expansão e consolidação do processo eletrônico.

Desde que o processo eletrônico se tornou protagonista na Justiça do Trabalho nos casos novos não houve redução da taxa de congestionamento; ao revés, ela atingiu seu ponto mais alto exatamente quando o processo eletrônico nos casos novos já ultrapassava a barreira de $90 \%$.

Não se defende o regresso ao processo físico. Isso seria de um obscurantismo atroz. Tampouco se nega as inúmeras vantagens que o processo eletrônico possui e que já se incorporaram ao sistema de justiça. O que pretende o artigo é demonstrar que a política judiciária de propagação do processo eletrônico como meio de se atingir celeridade e qualidade na prestação jurisdicional (Resolução 185/2013) não se confirmou na Justiça do Trabalho. Nesse contexto, exsurge a necessidade de adequação da política judiciária para que tenha efetiva relação com a realidade forense que se apresenta. Com efeito, o fenômeno da litigiosidade é muito mais complexo e não se resume a algumas variáveis como parecia acreditar o órgão de controle do Judiciário.

Ao não melhorar os indicadores referentes à taxa de congestionamento demonstra-se que a busca pela eficiência não foi atingida e, nesse contexto, percebe-se que o fundamento básico que originou a utilização do processo eletrônico não se comprovou.

4 Sobre as diversas facetas do vocábulo eficiência no âmbito jurídico confira Cabral (2019, p. 57 e ss.). 
Reitere-se para que não existam dúvidas: o processo eletrônico não é causa do aumento da taxa de congestionamento. O que se afirma é que ele não se consubstanciou como ferramenta apta a diminuir o congestionamento e, por consequência, melhorar a eficiência da Justiça Laboral.

Como o processo eletrônico não se mostrou hábil a sozinho alterar a taxa de congestionamento é imprescindível que o órgão de controle e organização do Judiciário, além de continuar na virtualização processual, passe a empregar estratégias de gestão mais modernas e aptas a entregar melhores resultados.

\section{POLÍTICAS JUDICIÁRIAS DO CNJ E ACCOUNTABILITY}

A Constituição Federal de 1988 conferiu substancial independência ao Poder Judiciário, assegurando garantias institucionais, funcionais e proteção à imparcialidade (Томіo; Robl Filho, 2013, p. 29-46); (SANTiso, 2004, p. 161-180), mas a ideia de accountabilitity possui marco temporal e normativo posterior: a Emenda Constitucional 45/2004 (Brasil, 2014). De fato, ela alterou o quadro então existente introduzindo um novo ator institucional - Conselho Nacional de Justiça - bem como trazendo inúmeras outras modificações no sistema de justiça. (Ribeiro; Arguelhes, 2016, p. 30-32).

O CNJ trouxe nova racionalidade ao Poder Judiciário, uma vez que concentrou em um órgão nacional a realização das políticas judiciárias, que outrora era fragmentada e feudalizada nos tribunais locais. O novo modelo constitucional conferiu ao CNJ, dentre outras atribuições, o controle (ArABTES et. al., 2010, p. 109-148) da atuação administrativa e financeira do Poder Judiciário, o cumprimento dos deveres funcionais pelos juízes, preenchendo, assim "lacunas de accountabilities presentes do arranjo constitucional de 1988" (Томіо; RoвL FILHO, 2013, p. 29-46), e, ainda, prevê a elaboração de relatório anual 
sobre a situação do Judiciário no país, bem como relatórios estatísticos sobre os processos e as sentenças proferidas. ${ }^{5}$

Passados quinze anos é indiscutível que a criação do $\mathrm{CNJ}$ foi uma medida alvissareira, porquanto rompeu com o insulamento dos tribunais locais, trouxe sistematização e nacionalização nas políticas judiciárias, diminuiu o corporativismo e realçou a necessidade de se conhecer estatisticamente cada tribunal. Nesse contexto, passa o CNJ a desenvolver a estatística judiciária como mecanismo indissociável de melhora dos serviços judiciários, afinal como destaca Marcelo Guedes Nunes (2016, p. 173): “Conhecer a realidade é o primeiro passo para transformá-la. A lição que subjaz a todo esforço de pesquisa empírica séria é que ninguém muda aquilo que ignora". No mesmo sentido ressalta Lee Loevinger (1971, p. 3-41): "A lição básica que todo advogado deve aprender é que 'precisamos saber o que estamos fazendo', como recentemente apontou o cientista Willian Vogt".

A questão que se coloca agora vai além: como o $\mathrm{CNJ}$ pode se submeter à fiscalização e sanção quando suas políticas não atingem o desiderato esperado?

A resposta pode estar no conceito de accountability social.

\subsection{Accountability: vertical, horizontal e social}

Para Shedler (1999, p. 26), accountability é a obrigação do agente público informar sobre suas atividades e justificá-las - answerability bem como a capacidade de se impor sanções para aqueles que violarem as regras de conduta - enforcement. ${ }^{7}$

5 Art. 103-B, $\$ 4^{\circ}$, incisos VI e VII da Constituição Federal.

6 Tradução livre de: "The basic lesson which lawyers must learn, as the scientist Willian Vogt has recently pointed out, is that "we need do know what we are doing"”.

7 Para Mark Bovens (2010): "Accountability is used as a synonym for many loosely defined political desiderata, such as good governance, transparency, equity, democracy, efficiency, responsiveness, responsability and integrity. Clèmerson Merlin Clève e Julia Ávila Franzoni (2013, p.15 e ss) asseveram que: "Accountability deve ser compreendida, portanto, como um conceito 
Dentro da dimensão da answerability observa-se, inicialmente, a existência de um binômio interativo, em virtude do qual os agentes públicos precisam informar que atos foram praticados, seguido de uma explicação sobre as razões da prática daqueles atos (o que e por quê). $\mathrm{O}$ primeiro aspecto do binômio consiste na possibilidade de exigir que sejam informados fatos confiáveis (dimensão informativa), enquanto o segundo elemento versa sobre as razões válidas apresentadas (dimensão argumentativa). (SCHEDlER, 1999, p.14-15).

Quanto ao aspecto do enforcement, Charles D. Kenney (2003, p.63) esclarece que a capacidade de sanções é essencial para o conceito de accountability, e que accountability sem sanções é de fato uma forma diminuta de accountability.

Guillermo O’Donnell (1998. p. 27-54) classifica a accountability em duas dimensões: a) vertical: quando existem eleições razoavelmente livres, periódicas e justas, assim como quando existe liberdade de opinião e associação. É essencial, ainda, que as reivindicações sociais ocorram sem o risco de coerção e que uma mídia razoavelmente livre faça a cobertura e denuncie atos de autoridades públicas; b) horizontal: se manifesta por intermédio de agências estatais que têm o direito e o poder legal e que estão de fato dispostas e capacitadas para "realizar ações, que vão desde a supervisão de rotina a sanções legais ou até o impeachment contra ações ou omissões de outros agentes ou agências do Estado que possam ser qualificadas como delituosas." (O’Donnell, 1998. p. 27-54).

No entanto, os conceitos clássicos de accountability se mostram parcialmente insuficientes (Tomio; Robl Filho, 2013, p. 29-46) aо

relacional que envolve, de um lado, a disponibilização de meios, dados e informações por parte do Poder Público e a criação de procedimentos que permitam a participação dos cidadãos na ação política e no controle de seus resultados e, de outro lado, estímulos orientados à transformação da postura passiva do cidadão em ativa". Para Enrique Peruzzotti (2010, p.2 e ss) "El concepto de rendición de cuentas refiere a la posibilidad de obligar a los funcionarios públicos a que informen sobre y justifiquen acerca de sus decisiones por un lado, $y$ de que puedan, por el otro lado, ser eventualmente sancionados por sus accionar" O conceito é, portanto, vinculado às ideias de transparência, publicidade, motivação e divulgação (CABRAL, 2015, p.149). 
CNJ, na medida em que o conceito vertical não incide - já que a instituição não se subordina a qualquer forma de escrutínio por meio de eleições populares ${ }^{8}$ - e a dimensão horizontal é mitigada (embora não inexistente ${ }^{9}$ ), afinal, ele é, em regra, a agência estatal de controle do Judiciário ${ }^{10}$.

Nesse contexto, ganha robustez o conceito de accountability social desenvolvido por Enrique Peruzzotti e Catalina Smulovitz (2002. p. 1-39). Entendem os autores argentinos que diante do déficit democrático na América Latina a solução tradicional de accountability vertical e horizontal proposta por O’Donnell é insatisfatória, porque: a) sujeitam-se à vontade da maioria; b) existe déficit informacional; c) há oportunidade única de escolha na eleição; d) pela ausência de um sistema intraestatal de pesos e contrapesos; e) pela falta de instituições autônomas; f) pela corrupção e g) dado o clientelismo latino americano. Defendem, assim, que juntamente com os modelos anteriores, seja implementada a accountability social, pautada nos movimentos sociais e na mídia, tendo como consequência a exposição pública do agente. A

8 A própria nomenclatura adotada pelo art. 103-B da Constituição Federal demonstra que a indicação dos Conselheiros não ostenta qualquer característica de eleição.

9 O CNJ se submete ao controle do Tribunal de Contas da União (TCU), órgão estatal que bem representa o exercício da accountability horizontal. De fato, como exemplo, apura-se por meio do Acórdão no 1.534/2019, emitido pelo Plenário do TCU, em análise ao processo eletrônico a cargo do $\mathrm{CNJ}$, que aquele órgão de controle externo (TCU) determinou ao Conselho da Justiça Federal (CJF) e ao Conselho Superior da Justiça do Trabalho (CJST) que apresentem, no prazo de 180 dias, plano de ação voltado ao aprimoramento da eficiência, da efetividade e da transparência das ações de implementação e operação dos sistemas de processo judicial eletrônico sob sua responsabilidade, indicando as medidas a serem adotadas, os responsáveis pelas ações e os respectivos prazos de implementação. (Vide https://portal.tcu.gov.br/imprensa/ noticias/tcu-aponta-atrasos-na-implementacao-do-processo-judicial-eletronico.htm) No entanto, apesar da existência desse controle, ele, por si só, não se mostra suficiente para que se possa falar de uma efetiva accountability sobre o CNJ.

10 De fato, como esclarece O'Donnell (1998. p. 27-54), para que accountability horizontal funcione tem que existir "agências estatais autorizadas e dispostas a supervisionar, controlar, retificar e/ou punir ações ilícitas de autoridades localizadas em outras agências estatais". 
vantagem desse formato é que não se subordina a questões da maioria, é mais específico e exerce controle permanente. O artigo foi escrito em 2002 e o argumento central ganha solidez no atual momento de redes sociais ativas e engajadas no debate político e público ${ }^{11}$. $\mathrm{Na}$ mesma toada afirma Robl Filho (2013, p. 262) que

A accountability vertical não eleitoral (social) constitui-se na relação de grupos da sociedade civil e da imprensa com os agentes estatais eleitos ou não eleitos. Por meio da busca e da análise de informações e justificações dos agentes estatais, os grupos sociais e a imprensa podem sancioná-los por não alcançar os resultados políticos almejados ou por violar o direito. As sanções da accountability social são a exposição pública dos agentes estatais e a formulação de denúncias aos órgãos de accountability horizontal responsáveis pela fiscalização dos agentes estatais."

Nesse contexto e diante da ausência de agências estatais que possam fiscalizar e sancionar o CNJ efetivamente, bem como considerando a inexistência de eleições, a accountability social desponta como medida hábil, na medida em que, como salienta Enrique Peruzzotti (2007, p. 2-21), ela inclui iniciativas que tem por objetivo denunciar déficit de desempenho e incompletude de atingimento das metas estabelecidas pelos agentes estatais.

\subsection{Quem guarda os guardas?}

A adoção do processo eletrônico como ferramenta responsável pela redução da taxa de congestionamento e, por consequência, de maior eficiência nos tribunais não se realizou e, a despeito disso, inexiste outra política judiciária substitutiva e/ou complementar pelo

11 Os autores já mencionavam o risco da influência econômica, dos excessos da mídia e do descrédito público, bem como a subversão de interesses por minorias ruidosas, o que deve ser observado e evitado nesse modelo de accountability. 
CNJ de mesma envergadura a fim de aprimorar a performance dos atores judiciais.

Somado a isso, na perspectiva de transparência ínsita à accountability, verifica-se uma divulgação de dados que reflete tão somente sua faceta procedimental, mas que não revela a substância, as implicações reais. Efetivamente, trabalha-se apenas com a divulgação das estatísticas, mas não existe um compromisso com a divulgação dos resultados decorrentes das expectativas noticiadas - verberou-se que o processo eletrônico traria maior eficiência, mas nada se noticia quanto ao (não) cumprimento dessa promessa. Não há, portanto, uma transparência substancial.

$\mathrm{E}$, nesse contexto de ausência de mais agências estatais (além do TCU, conforme apontado em nota de rodapé) a quem o CNJ preste contas, cabe à sociedade fiscalizar a eficiência das políticas judiciárias implementadas pelo órgão. Isso pode (deve) ser feito pelas associações de juízes, OAB, sindicato de servidores, mídia especializada e geral, defensoria pública, cidadãos, enfim, todo e qualquer usuário do sistema de justiça. Embora não exista uma sanção específica na hipótese de a prestação de contas ser insuficiente, a acccountability social indica como meio de se atingir tal circunstância a exposição pública do agente ou órgão que praticou o ato.

Nesse diapasão, desponta como essencial a revisão da política judiciária que o CNJ elegeu a fim de aperfeiçoar o andamento da tramitação processual, sendo certo que a instituição do processo eletrônico, conquanto vantajosa em diversos ângulos, não se demonstrou apta a melhorar a eficiência do Judiciário, considerando a métrica traçada pelo CNJ, ou seja, a taxa de congestionamento.

É certo que a instituição do CNJ teve como objetivo o controle e o aprimoramento da atuação judicial (Ribeiro; Arguelhes, 2015, p. 464-503) e isso tem que ser monitorado, fiscalizado, motivado e, quando não alcançado, sancionado. Embora a forma de sanção - exposição pública - seja mais branda, no momento é a única existente e deve ser utilizada. O que não se pode permitir é a continuidade de 
uma política que já demonstrou não atingir os objetivos para os quais foi estabelecida.

Se o processo eletrônico não teve o potencial que lhe foi atribuído, no sentido de impactar vigorosamente o congestionamento processual, é indispensável que outras políticas sejam desenhadas e instituídas, sobretudo porque a morosidade está arraigada no Judiciário e é um dos, senão o maior, desafio a ser superado. Há boa literatura sendo produzida no sentido de que o arcaico método de gestão cartorial reflete de forma significativa no tempo de duração das demandas (Bondiman, 2013, p. 319); (Silva, 2013, p. 104); (Barbosa; Beckers, 2017, p. 217-218); (Cunha, 2013, p. 104); (Cunha; Gabbay, 2013, p. 132); (Rotta et al. 2013, p. 125-154), mas até o momento somente existem atos normativos genéricos do $\mathrm{CNJ}$ e que não tiveram o condão de alterar o formato existente.

Considerando que em um ambiente democrático não pode existir um unchecked power/agente (Томio; Robl Filho, 2013, p. 29-46), e diante do arranjo institucional em que se insere o CNJ, a accountability social pode ser o mecanismo de controle e sanção para fiscalizar a implementação, desenvolvimento e atingimento das metas propostas pelas políticas públicas arquitetadas, sendo certo que é necessária a utilização de novas estratégias para a redução da taxa de congestionamento, porquanto o processo eletrônico não atingiu esse desiderato.

\section{CONCLUSÃO}

1) No período objeto de investigação (2012 - 2017) a Justiça do Trabalho atingiu 96,3\% de casos novos eletrônicos, alcançando, assim, a quase totalidade de virtualização nas novas demandas.

2) Sistema de justiça eficiente é aquele que possui baixa taxa de congestionamento, porquanto tem a capacidade de solucionar (julgar/baixar) com celeridade e qualidade as demandas que lhe são submetidas, metabolizando os casos novos recebidos e, ainda, com redução do resíduo/estoque processual. 
3) O incremento do processo eletrônico não se corporificou em melhora da taxa de congestionamento, o que significa que não houve ganho de eficiência e no desempenho dos atores judiciais.

4) A morosidade, ineficiência e taxa de congestionamento do sistema de justiça são fenômenos complexos e multicausais. Nesse contexto, a implementação e desenvolvimento do processo eletrônico não se mostrou suficiente para melhorar tais indicadores na Justiça do Trabalho.

5) A promessa do CNJ materializada na Resolução 185/2013 no sentido de que o processo eletrônico traria mais celeridade e qualidade na tramitação processual não se concretizou.

6) O CNJ padece de déficit de accountability, porquanto as políticas judiciárias que implementa não se submetem a qualquer forma de escrutínio, validação, fiscalização e sanção.

7) Considerando o arranjo institucional onde se insere o CNJ, os mecanismos clássicos de accountability (vertical e horizontal) têm aplicação mitigada a este órgão, razão pela qual a dimensão de accountability social deve ser impulsionada a fim de que se viabilize um instrumento de controle e sanção.

8) A accountability social deve ser exercida por todos os usuários do sistema de justiça com o desiderato de aprimorar a arquitetura do CNJ, exigindo prestação de contas acerca de todas as políticas judiciárias implementadas e, aplicando sanção, quando elas não alcançam os objetivos propostos.

\section{REFERÊNCIAS}

ARAGÃO, Egas Moniz. Estatística Judiciária. Revista Forense: Rio de Janeiro, v. 365, 2003.

ARANTES, Rogério Bastos; LOUREIRO, Maria Rita; COUTO, Cláudio; TEIXEIRA, Marco Antônio Carvalho. Controles democráticos sobre 
a administração pública no Brasil: Legislativo, Tribunais de Contas, Judiciário e Ministério Público. In: LOUREIRO, Maria Rita; ABRUCIO, Fernando Luiz; PACHECO, Regina Silva (org.). Burocracia e Política no Brasil: desafios para a ordem democrática no século XXI. Rio de Janeiro: Editora FGV, 2010. p. 109-148.

BARBOSA, Claudia Maria; BECKERS, Richard. A distribuição do tempo de duração do processo entre os dos atores processuais. In: BARBOSA, Claudia Maria; PAMPLONA, Danielle Anne (Org.). Limites e possibilidades da legitimidade e eficácia da prestação jurisdicional no Brasil. Curitiba: Letra da Lei, 2017. v. 1.

BONDIMAN, Carolina. Serventias judiciais e tempos do processo. In: CUNHA, Alexandre dos Santos; SILVA, Paulo Eduardo Alves da (Coord.). Pesquisa empírica em direito. Anais do I Encontro de Pesquisa Empírica em Direito, Ribeirão Preto, 29 e 30 de setembro de 2011. Rio de Janeiro: Ipea, 2013.

BOVENS, Mark. Two concepts of accountability. Disponível em: https:// www.tandfonline.com/doi/abs/10.1080/01402382.2010.486119. Acesso em: 27 nov. 2015.

BRASIL. Emenda Constitucional n. 45, de 30 de dezembro de 2004. Altera dispositivos dos arts. 5', 36, 52, 92, 93, 95, 98, 99, 102, 103, 104, 105, 107, 109, 111, 112, 114, 115, 125, 126, 127, 128, 129, 134 e 168 da Constituição Federal, e acrescenta os arts. 103-A, 103B, 111-A e 130-A, e dá outras providências. Brasília: Diário Oficial da União de 31 dez. 2004. Disponível em: http://www.planalto.gov.br/ccivil_03/Constituicao/Emendas/Emc/ emc45.htm. Acesso em: 02 set. 2015.

CABRAL, Flávio Garcia. Os fundamentos políticos da prestação de contas estatal. Revista de Direito Administrativo - RDA, Rio de Janeiro, v. 270, p. 147-169, set./dez. 2015.

CABRAL, Flávio Garcia. O conteúdo jurídico da eficiência administrativa. Belo Horizonte: Fórum, 2019.

CLÉVE, Clémerson Merlin; FRANZONI, Julia Ávila. Administração Pública e a nova Lei de Acesso à Informação. Interesse Público. Belo Horizonte, v. 15, n. 79, p. 15-40, maio/jun. 2013.

CONSELHO NACIONAL DE JUSTIÇA. Disponível em: http://www. cnj.jus.br/atos-normativos?documento=1933. Acesso em: 24 jun. 2019. 
CONSELHO NACIONAL DE JUSTIÇA. Disponível em: http://www. cnj.jus.br/gestao-e-planejamento/gestao-e-planejamento-do-judiciario/ indicadores/486-gestao-planejamento-e-pesquisa/indicadores/13659-03-taxa-de-congestionamento. Acesso em: 25 jun. 2019.

CONSELHO NACIONAL DE JUSTIÇA. Disponível em: http://www. cnj.jus.br/files/conteudo/arquivo/2017/09/e5b5789fe59c137d43506b2e4ec4ed67.pdf. Acesso em: 25 jun. 2019.

CONSELHO SUPERIOR DA JUSTIÇA DO TRABALHO. Disponível em: http://www.csjt.jus.br/c/document_library/get_file?uuid=9b2979a4-718e-4f8a-ab34-65cb9da49d9b\&groupId=955023. Acesso em: 24 jun. 2019.

CONSELHO SUPERIOR DA JUSTIÇA DO TRABALHO. Disponível em: https://juslaboris.tst.jus.br/bitstream/handle/20.500.12178/102716/2017_ res0185_csjt_compilado.pdf?sequence $=4 \&$ isAllowed=y. Acesso em: 27 jun. 2019.

COSTANDRADE, Pedro Henrique Arazine de Carvalho; SILVA JÚNIOR, Gilson G.; GICO JÚNIOR, Ivo T. Panorama do judiciário brasileiro: crise e números. In: RIBEIRO, Gustavo Ferreira; GICO JÚNIOR, Ivo T. (Coord.). O jurista que calculava. Curitiba: CRV, 2013. p. 37-70.

CUNHA, Alexandre dos Santos. Execução fiscal na justiça federal. In: CUNHA, Alexandre dos Santos; SILVA, Paulo Eduardo Alves da (Coord.). Pesquisa empírica em direito. Anais do I Encontro de Pesquisa Empírica em Direito, Ribeirão Preto, 29 e 30 de setembro de 2011. Rio de Janeiro: Ipea, 2013.

CUNHA, Luciana G; GABBAY, Daniela. Morosidade e demandas repetitivas. In: CUNHA, Alexandre dos Santos; SILVA, Paulo Eduardo Alves da (Coord.). Pesquisa empírica em direito. Anais do I Encontro de Pesquisa Empírica em Direito, Ribeirão Preto, 29 e 30 de setembro de 2011. Rio de Janeiro: Ipea, 2013.

EFING, Antônio Carlos; MARQUES FILHO, Lourival Barão. Pesquisa empírica e direito do consumidor: uma aproximação necessária. Revista de direito do consumidor. v.108/2016, p. 439-457, nov-dez/2016.

EISENBERG, Theodore; LANVERS, Charlotte. What is the Settlement Rate and Why Should We Care? Cornell Law Faculty Publications. Paper 203. 2009. Disponível em: http://scholarship.law.cornell.edu/facpub/203. Acesso em: 30 jun 2019. 
EPSTEIN, Lee; KING, Gary. Pesquisa empírica em direito [livro eletrônico]. São Paulo: Direito GV, 2013.

FIDELIS, Claudia. O processo judicial eletrônico e seu reflexo quantitativo na taxa de congestionamento da justiça estadual do Brasil. Dissertação de mestrado. Curitiba (PUC/PR), 2018.

HARTMANN, Ivar A.; KELLER, Clara Iglesias; CHADA, Daniel; VASCONCELOS, Guilherme; NUNES, José Luiz; CARNEIRO, Letícia; CHAVES, Luciano; BARRETO, Matheus; CORREIA, Fernando; ARAÚJO, Felipe. O impacto no sistema prisional brasileiro da mudança de entendimento do Supremo Tribunal Federal sobre execução da pena antes do trânsito em julgado no HC 126.292/SP - um estudo empírico quantitativo. Revista de Direito Econômico e Socioambiental, Curitiba, v. 9, n. 1, p. 399-426, jan./abr. 2018.

HOLMES, O.W. The Path of Law. Harvard Law Review, n. 10, p. 457, 469 (1897). Disponível em: http://www.constitution.org/lrev/owh/path_law. htm. Acesso em: 23 jun. 2019.

JUSTIÇA EM NÚMEROS 2013: ano-base 2012/Conselho Nacional de Justiça - Brasília: CNJ, 2013.

JUSTIÇA EM NÚMEROS 2014: ano-base 2013/Conselho Nacional de Justiça - Brasília: CNJ, 2014.

JUSTIÇA EM NÚMEROS 2015: ano-base 2014/Conselho Nacional de Justiça - Brasília: CNJ, 2015.

JUSTIÇA EM NÚMEROS 2016: ano-base 2015/Conselho Nacional de Justiça - Brasília: CNJ, 2016.

JUSTIÇA EM NÚMEROS 2017: ano-base 2016/Conselho Nacional de Justiça - Brasília: CNJ, 2017.

JUSTIÇA EM NÚMEROS 2018 ano-base 2017/Conselho Nacional de Justiça - Brasília: CNJ, 2018.

KANT DE LIMA, Roberto; BAPTISTA, Bárbara Gomes Luppeti. O desafio de realizar pesquisa empírica no direito: uma contribuição antropológica. Disponível em: http://filoinfo.net/disciplinasonline/pluginfile. php/4485/mod_resource/content/1/o_desafio_de_realizar_pesquisa_empirica_no_direito.pdf. Acesso em: 20 jun. 2019. 
KAZMIER, Leonard J. Estatística aplicada à economia e administração. Trad. Carlos Augusto Crucius; Rev. Técnica Jandyra M. Fachel. São Paulo: Pearson Makron Books, Coleção Schaum, 2004.

KENNEY, Charles D.. Horizontal accountability: concepts and conflicts. In: Democratic accountability in Latin America. New York: Oxford University Press, 2003. p.55-76.

LOEVINGER, Lee. The next step forward. Jurimetrics Journal. vol. 12, n. 1 (September 1971), pp. 3-41. https://www.jstor.org/stable/29761220?seq=1\#page_scan_tab_contents. Acesso: 29 set. 2019.

MARTIN-GUZMÁN, Pilar. The growing demand for statistics: challenges and opportunities. In: Statistics, knowledge and policy: key indicators to inform decision making. Paris: OECD Publications, 2005. p. 513-521. NALINI, José Renato. É desprezado porque é o último? Ou é o último porque é desprezado? In: ANDREUCCI, Ana Claudia Pompeu Torezan... [et al.]. Direito humanos: perspectivas e reflexões para o Século XXI. São Paulo: Ltr, 2014. p. 250-258

NUNES, Marcelo Guedes. Jurimetria: como a estatística pode reinventar o direito. São Paulo: RT, 2016.

O'DONNELL, Guillermo. Accountability horizontal e novas poliarquias. Lua Nova, São Paulo, n.44. p. 27-54, 1998.

PERUZZOTTI, Enrique. Rendición de cuentas, participación ciudadana y agencias de control en América Latina. In: Conferência da XVII Assembleia Geral Ordinária das DAS OLACEFS, 2007, Santo Domingo. p. 2-21. Disponível em: <http://acij.org.ar/wp-content/uploads/2010/12/ peruzzotti-rendicion-de-cuentas-participacion-ciudadana-y-agencias-de-control-en-america-latina. pdf. Acesso: 27 jun. 2019.

PERUZZOTTI, Enrique; SMULOVITZ, Catalina. Accountability social: La otra cara del control. In: PERUZZOTTI, Enrique; SMULOVITZ, Catalina (Eds.). Controlando la Política. Ciudadanos y Medios en las Democracias Latinoamericanas. Buenos Aires: Grupo Editorial Temas, 2002. p. 1-39.

ROBL FILHO, Ilton Norberto. Conselho Nacional de Justiça: estado democrático de direito e accountability. São Paulo: Saraiva, 2013.

RIBEIRO, Leandro Molhano; ARGUELHES, Diego Werneck. CNJ: Captura Nacional da Justiça? Conjuntura Econômica (Rio de Janeiro), v. 70, p. 30-32, 2016. 
RIBEIRO, Leandro Molhano; ARGUELHES, Diego Werneck. O Conselho no Tribunal: Perfil quantitativo das ações contra o CNJ junto ao STF / The Council in the Court: A quantitative profile of challenges to the CNJ decisions before the STF. Revista Direito e Práxis, v. 6, p. 464-503, 2015.

ROTTA, M. J. R., VIEIRA, P., ROVER, A. J, SEWALD JUNIOR, E. Aceleração Processual e o Processo Judicial Digital: um Estudo Comparativo de Tempos de Tramitação em Tribunais de Justiça. Revista Democracia Digital e Governo Eletrônico, n. 8, p. 125-154, 2013.

SANTISO, Carlos. Economic reform and judicial governance in Brazil: balancing independence with accountability. In: GLOPPEN, Siri, GARGARELLA, Roberto; SKAAR, Elin (org.). Democratization and the judiciary: the accountability function of courts in new democracies. Frank Cass Publishers, London, UK e Portland, Or, USA, 2004. p. 161-180.

SCHEDLER, Andreas. Conceptualizing Accountability. In: SCHEDLER, Andreas; DIAMOND, Larry Jay; PLATTNNER, Marc. (org.). The Self-Restraining State. Power and Accountabílity in New Democracies. Boulder y Londres: Lynne Rienner Publishers, 1999. p.13-28.

SHAFFER, Gregory; GINSBURG, Tom. A reviravolta empírica na doutrina do direito internacional. Revista de Estudos Empíricos em Direito. Brazilian Journal of Empirical Legal Studies. vol. 2, n. 2, p. 192-235, jan 2015.

SILVA, Paulo Eduardo Alves da. Gestão e funcionamento dos cartórios judiciais. In: CUNHA, Alexandre dos Santos; SILVA, Paulo Eduardo Alves da (Coord.). Pesquisa empírica em direito. Anais do I Encontro de Pesquisa Empírica em Direito, Ribeirão Preto, 29 e 30 de setembro de 2011. Rio de Janeiro: Ipea, 2013.

TOMIO, Fabrício Ricardo de Limas; ROBL FILHO, Ilton Norberto. Accountability e independência judiciais: uma análise da competência do Conselho Nacional de Justiça (CNJ). Revista de Sociologia e Política [online], v.21, n.45, p. 29-46, 2013.

TRIBUNAL SUPERIOR DO TRABALHO. Disponível em: http:// www.tst.jus.br/web/estatistica/vt/recebidos-e-julgados. Acesso em: 24 jun 2019. 
TRIBUNAL SUPERIOR DO TRABALHO. Disponível em: http://www. tst.jus.br/web/estatistica/vt/prazos. Acesso em: 24 jun 2019.

YEUNG, Luciana. Além dos 'achismos', do senso comum e das evidências anedóticas: uma análise econômica do judiciário brasileiro. Tese de doutorado. São Paulo (USP), 2010.

YEUNG, Luciana; AZEVEDO, P. F. Beyond conventional wisdom and anedoctal evidence: measuring efficiency of brazilian courts. In: annual conference of the international society for new institutional economics (Berkeley:2009). Papers Disponível em: https://extranet.sioe.org/uploads/ isnie2009/yeung_azevedo.pdf. Acesso em: 24 jun. 2019.

WATANABE, Kazuo. A pesquisa em direito e a pesquisa em ciências sociais. In: CUNHA, Alexandre dos Santos; SILVA, Paulo Eduardo Alves da (Coord.). Pesquisa empírica em direito. Anais do I Encontro de Pesquisa Empírica em Direito, Ribeirão Preto, 29 e 30 de setembro de 2011. Rio de Janeiro: Ipea, 2013.

\section{LOURIVAL BARÃO MARQUES FILHO}

Mestre e doutorando pela PUC/PR, em Direito Socioambiental. Coordenador e professor da especialização do curso de pós-gradução em Direito, Processo do Trabalho e Direito Previdenciário da Escola dos Magistrados do Paraná. Juiz do Trabalho, Titular da $18^{\mathrm{a}}$ Vara de Curitiba/PR.

Endereço profissional: Avenida Vicente Machado, 400, Centro, Curitiba, Paraná, CEP 80420-010, Brasil.

ORCID ID: http://orcid.org/0000-0002-3806-1867

E-MAIL: lourivalbaraomarques@gmail.com

\section{FLÁVIO GARCIA CABRAL}

Pós-Doutor em Direito pela PUC-PR; Doutor em Direito Administrativo pela PUC-SP; Professor da UNAES-MS, EDAMP e da UNIGRAN (MS); Procurador da Fazenda Nacional. 
Endereço profissional: Alameda Cedro Vermelho, 1211, Campo Grande, MS, CEP 79046-006, Brasil.

ORCID ID: http://orcid.org/0000-0002-8128-314X

E-mAIL:flaviocabral_@hotmail.com

Recebido: 30/09/2019

Aceito: 29/11/2021

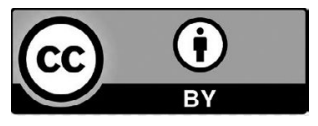

Este trabalho está licenciado sob uma licença Creative Commons Attribution 4.0 International License.

Autores e autoras cedem à Revista Sequência direitos exclusivos de primeira publicação, ficando o trabalho licenciado sob a Creative Commons Attribution 4.0 International License. A licença autoriza que terceiros remixem, adaptem e ou criem a partir do trabalho publicado, indicando o crédito ao trabalho original e sua publicação inicial. Os autores têm permissão para assumir contratos adicionais em separado, com distribuição não exclusiva da versão publicada na Revista Sequência, indicando, de todo modo, a autoria e publicação inicial neste periódico. 